See Article page 121.

\section{Commentary: A new PORT in the stage IIIA N2 non-small cell lung cancer storm}

\author{
Matthew J. Ashbrook, MD, MPH, ${ }^{\mathrm{a}}$ and \\ Anthony W. Kim, MD ${ }^{a, b}$
}

Patients with stage III non-small cell lung cancer (NSCLC) have a heterogenous set of lesions warranting different and multiple treatment modalities. Although many with stage IIIA N2 disease will receive definitive systemic therapy with radiation therapy or neoadjuvant systemic therapy with or without the addition of radiation therapy, some patients with stage IIIA N2 disease may undergo surgery and adjuvant therapy that may or may not include postoperative radiotherapy (PORT). As many clinicians dealing with locoregionally advanced lung cancer are aware, data from more than 20 years ago failed to show a definitive benefit from PORT, and thus today, PORT is not universally used for resected stage III disease. ${ }^{1}$ In their new meta-analysis, Harling and colleagues ${ }^{2}$ provide a beacon to help guide us through the stage IIIA N2 storm. Their analysis may generate renewed vigor in the study of stage IIIA N2 NSCLC treatment, as it suggests that PORT may be beneficial in the treatment of NSCLC with this disease stage.

Harling and coauthors have culled through a tsunami of data to provide a meta-analysis with the stated goal of determining whether modern PORT provides an additional survival advantage beyond observation for patients with completely resected stage IIIA N2 disease and who have

From the ${ }^{\mathrm{a} D e p a r t m e n t}$ of Surgery and ${ }^{\mathrm{b}}$ Division of Thoracic Surgery, Keck School of Medicine, University of Southern California, Los Angeles, Calif.

Disclosures: The authors reported no conflicts of interest.

The Journal policy requires editors and reviewers to disclose conflicts of interest and to decline handling or reviewing manuscripts for which they may have a conflict of interest. The editors and reviewers of this article have no conflicts of interest.

The views expressed in this manuscript reflect the results of research conducted by the authors and do not necessarily reflect the official policy or position of the Department of the Navy, Department of Defense, or the US Government.

Received for publication Jan 13, 2021; revisions received Jan 13, 2021; accepted for publication Jan 13, 2021; available ahead of print Feb 24, 2021.

Address for reprints: Anthony W. Kim, MD, Keck School of Medicine, University of Southern California, 1510 San Pablo St, Suite 514, Los Angeles, CA 90033

(E-mail: anthony.kim@med.usc.edu).

JTCVS Open 2021;5:131-2

2666-2736

Copyright (C) 2021 The Authors. Published by Elsevier Inc. on behalf of The American Association for Thoracic Surgery. This is an open access article under the CC BY-NCND license (http://creativecommons.org/licenses/by-nc-nd/4.0/).

https://doi.org/10.1016/j.xjon.2021.01.008

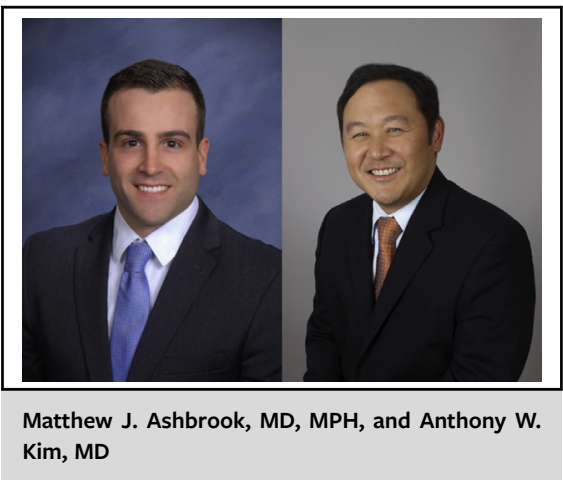

CENTRAL MESSAGE

This meta-analysis provides hope

that in the current era of lung

cancer care, administering PORT

may be a viable option in navi-

gating the seas of the stage IIIA

N2 NSCLC storm.

received adjuvant chemotherapy. A total of 10 studies met their final inclusion criteria, which included 3 prospective studies, 4 retrospective studies, and 3 national database analyses, yielding a pooled dataset of 18,077 patients. The $30.2 \%$ of patients receiving PORT had significantly better overall and disease-free survival at the 1-year, 3-year, and 5 -year timepoints. With improvements in staging accuracy, surgical techniques, and radiotherapy, the authors advocate for considering PORT in conjunction with adjuvant chemotherapy for the treatment of stage IIIA N2 NSCLC.

The determination for adjuvant therapy reflects a variety of patient factors, such as performance status; surgical considerations, such as the extent of $\mathrm{N} 2$ disease resected or remaining; and tumor characteristics, such as histological features, among several other considerations that remain unknown and is a limitation of many studies, including this one. In addition, N2 disease that is discovered during preoperative staging rather than detected incidentally during lymph node dissection may be associated with a different natural history. Finally, the meta-analysis also avoids diving into the typhoon-like debate that swirls around the role of neoadjuvant therapy, without which proceeding to surgery represents a decision tantamount to falling into deep water without a life vest for some clinicians.

While not entirely uncharted waters, the meta-analysis by Harling and colleagues represents a laudable repeat voyage into the ocean of doubt that circles around PORT for NSCLC. Ultimately, they deliver "see-worthy" findings that may lead 
to improvements in treating stage IIIA N2 NSCLC specifically. For navigating the current following surgical resection of these lesions, we are provided with encouraging evidence that adjuvant chemotherapy should be moored to PORT. With the evolution of immunotherapy and other forms of systemic treatment for NSCLC and ongoing advances in radiation therapy, there may be a perfect storm brewing for PORT.

\section{References}

1. PORT Meta-analysis Trialists Group. Postoperative radiotherapy in nonsmall-cell lung cancer: systematic review and meta-analysis of individual patient data from nine randomised controlled trials. Lancet. 1998;352: 257-63.

2. Harling L, Jayakumar S, Ashrafian H, Bille A, Toufektzian L, Smith D. Mediastinal radiotherapy after adjuvant chemotherapy for resected non-small cell lung cancer with N2 lymphadenopathy: a novel meta-analysis. J Thorac Cardiovasc Surg Open. 2021;5:121-30. 